\title{
Interaction and variation of isotopic age, temperature, organic and inorganic solutes in Hungarian thermal waters
}

\author{
József Fekete, Csanád Sajgó \\ Institute for Geochemical Research \\ Hungarian Academy of Sciences, Budapest
}

\author{
Zoltán Kárpáti \\ Budapest
}

Magdolna Hetényi

University of Szeged, Szeged

\author{
István Horváth \\ Geological Institute of Hungary, Budapest
}

István Vető
Budapest

\begin{abstract}
The geochemical facies of Hungarian thermal waters were the object of this study. Samples were separated into groups by relative ages $\left(\delta^{18} \mathrm{O}\right.$ values). Mature and immature subgroups were formed on the basis of dissolved (semi)volatile organic compounds. The oldest (connate) waters form one group with a small number of samples. The subgroups containing different small molecular-sized soluble aromatics differ sharply in their chemical features (sodium, hydrogen carbonate, iodine, ammonium etc. content). The origin of the organic matter may differ in the subgroups as inferred by their different $\delta^{18} \mathrm{O}$ values and ten times greater halogen contents.

Our results show that the decomposition of organic matter produces small molecular-sized aromatic compounds and also influences the amounts of inorganic components in thermal waters, through the increase of feldspar hydrolysis and carbonate dissolution.
\end{abstract}

Key words: hydrogeochemistry, thermal waters, $\delta^{18} \mathrm{O}$, organic matter, aromatic compounds

\section{Introduction}

Thermal waters in the Pannonian Basin may contain high amounts of dissolved organic material.

Humic substances and aromatic content of some tens of Hungarian thermal waters have been described qualitatively by Kárpáti et al. (1995, 1996a,b, 1999).

Addresses: J. Fekete, Cs. Sajgó: H-1112 Budapest, Budaörsi út 45, Hungary, e-mail: feketej@geochem.hu, sajgo@geochem.hu

I. Horváth: H-1143 Budapest, Stefánia út 14, Hungary, e-mail: horvathi@mafi.hu Z. Kárpáti: H-1032 Budapest, Kiscelli u. 18, Hungary, e-mail: karpati-zoltan@t-online.hu I. Vetô: H-1026 Budapest, Balogh Ádám u. 18/c, Hungary, e-mail: vetoie3840@gmail.com M. Hetényi: H-6722 Szeged, Egyetem u. 2-6, Hungary, e-mail: hetenyi@geo-u-szeged.hu Received: April 2, 2010; accepted: August 8, 2010 
According to these authors, the concentration of humic substances usually decreases and those of the aromatic compounds increases with increasing water temperature. The appearance of the different homologue series is temperaturedependent. Aromatic hydrocarbons appeared at a threshold temperature of $\sim 80^{\circ} \mathrm{C}$, followed by phenols at $\sim 90^{\circ} \mathrm{C}$, and in the hottest waters $\left(>90^{\circ} \mathrm{C}\right)$ fatty acids were identified. In the homologue series demethylation was associated with increasing temperature, leading to a decrease of the relative abundances of the higher molecular-sized members and a clear predominance of the compounds containing less carbon atoms.

Recently Varsányi et al. (2002) discussed quantitatively the contribution of humic substances, acetate, propionate and aromatic compounds to organic material dissolved in thermal waters of SE Hungary, mostly south of the Körös River.

Vetô et al. (2004a) reported concentrations and isotopic composition of methane in thermal waters of SE Hungary and discussed pathways of bacterial methanogenesis.

In an ongoing project, we are focusing on aromatic compounds but thermal waters taken from north of the Körös River and those from northern and southwestern parts of the country are also studied. In this communication we present the chemical and isotopic signatures of 38 thermal water samples. More than 500 aromatic compounds (PAHs, phenols, heteroaromatics) and relatively long carbon-chain fatty acids were found and identified in half of them. The water samples were grouped according to their oxygen isotope composition $\left(\delta^{18} \mathrm{O}\right.$ value in $\%$ VSMOW). The difference in the $\delta^{18} \mathrm{O}$ value can be tentatively used as an indicator of relative groundwater age. In some cases it is influenced by water mixing or at high temperatures overprinted by rock-water interaction processes.

Aromatic contents of thermal water (sub)groups (separated by oxygen stable isotope ratios and divided into subgroups on the basis of aromatics) are compared. Inorganic, organic and isotopic parameters were measured to study the temperature dependence of the organic and inorganic features and to obtain information on the relationship between organic and inorganic compounds or facies.

The aquifers are mostly of Late Pannonian (Late Miocene) age; the depths of screened intervals vary between 411 and 2264 meters. Outflow temperatures (from $38{ }^{\circ} \mathrm{C}$ to $99{ }^{\circ} \mathrm{C}$ ) do not show strict correlation with depth, which can be explained by the different geologic settings and geothermal gradient values. It is important to notice that the great majority of studied wells produce water from several aquifers. The distance separating the top of the uppermost and the bottom of the lowermost aquifer can be as great as $600 \mathrm{~m}$. For this reason we applied outflow temperatures instead of bottom-hole ones. Effective temperatures $(\sim$ weight average aquifer parameters of different temperature and contribution) are $15^{\circ} \mathrm{C}$ to $35^{\circ} \mathrm{C}$ higher then outflow temperatures depending on depth and production intensity and interval. These facts can result in some uncertainties in the interpretation of data.

Most of the water samples are of sodium-hydrogen-carbonate type, while the three "oldest" $\delta^{18} \mathrm{O}_{\mathrm{SMOW}}$ close to $0 \%$ ones are of sodium-chloride type. 


\section{Geologic setting}

The samples were taken in representative localities in Hungary with different watershed lithologies (Fig. 1). Most of the samples were taken from southeastern Hungary. In the Pannonian Basin the Quaternary and Tertiary sediments can reach a thickness of 7,000 $\mathrm{m}$, depending on the bedrock morphology. The Upper Pannonian and younger formations differ from the Lower Pannonian both in petrological and hydrogeologic features. The gravelly, sandy delta sediments of the Upper Pannonian were found to be prevalent and are characterized by good permeability. The meteoric (and paleometeoric) waters reach a great depth in a short time. The top of the Lower Pannonian mostly consists of siliciclastic, finegrained brackish and lacustrine sediments characterized by extremely low porosity and permeability.

Basin subsidence and burial is more rapid than sediment compaction and connate waters are trapped in the pores. These are partly the waters of the original depositional environment: the Pannonian Lake. As the porosity decreases (because of compaction and cementation) the connate waters are squeezed out of the pores and an overpressured zone (an aquiclude potential surface) is formed at the depth of 1,500 to $2,500 \mathrm{~m}$. This is the greatest depth meteoric waters can reach (Tóth and Almási 2001). Above this the connate waters mix with meteoric waters and change their isotopic and chemical properties. The attenuation of the former brackish waters, the rock-water interaction, the ionchange and filtering properties of clayey and other fine-grained deposits and - as will be demonstrated - the amount and maturity of the dissolved organic matter, determines the composition of the waters. Chemical parameters are shown in Table 1 . Some of the samples were previously studied for their methane content (Vető et al. 2004a).

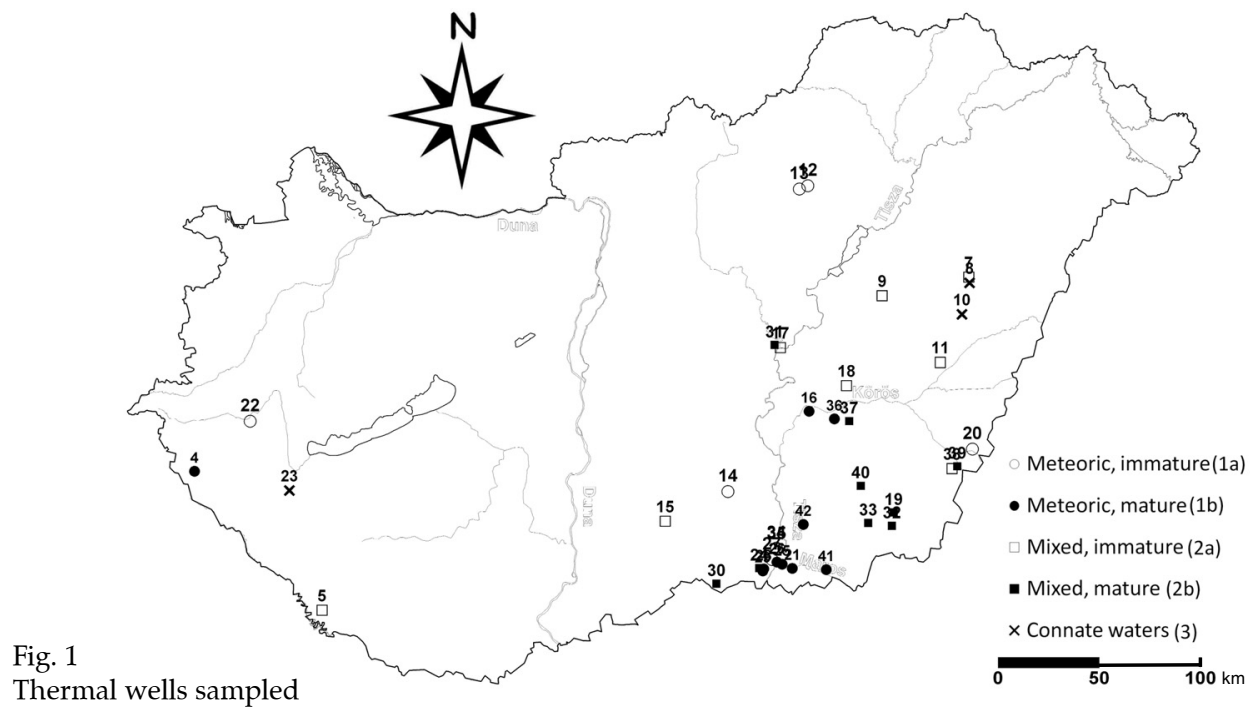


272 J. Fekete et al.

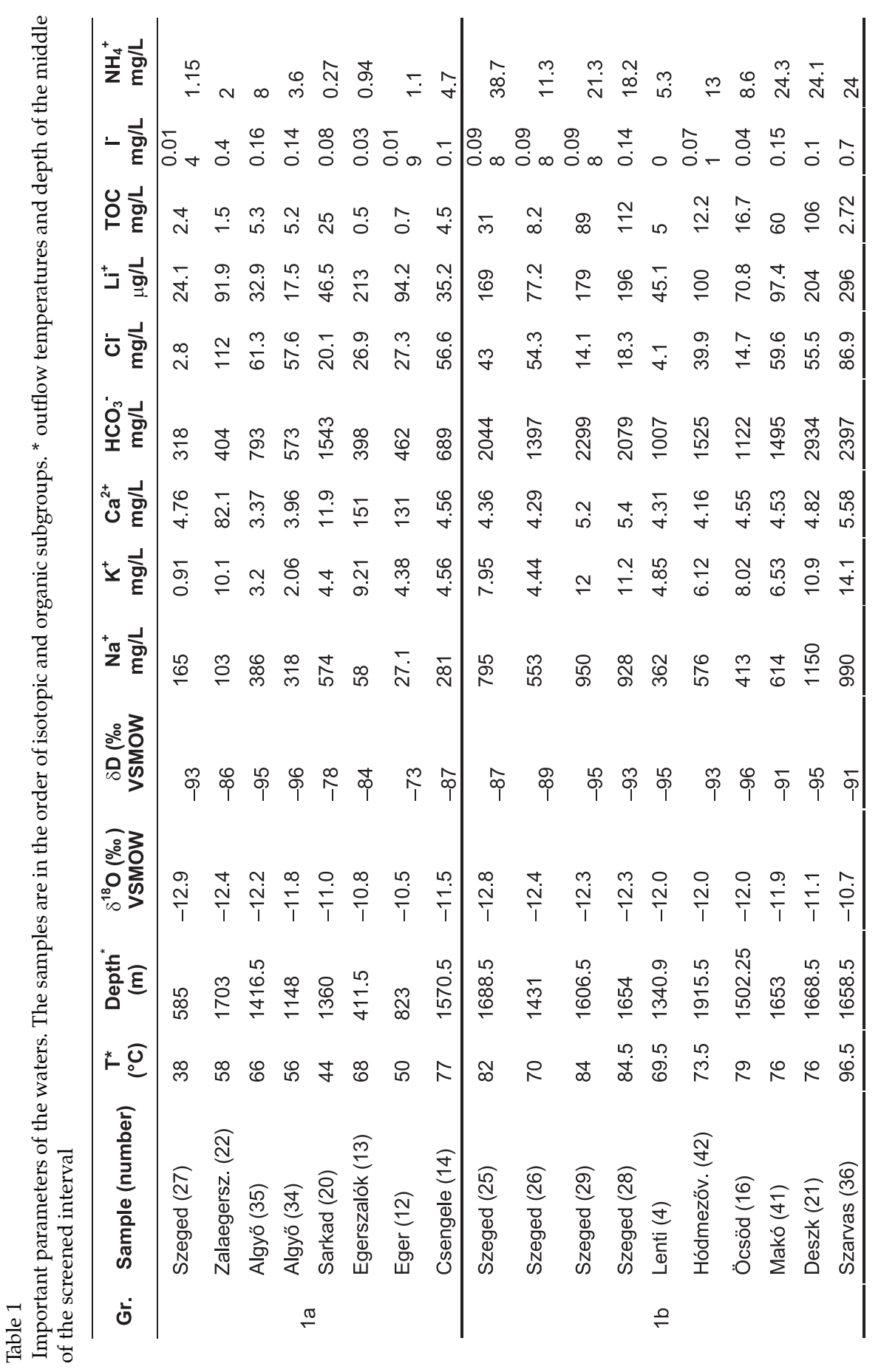

Central European Geology 52, 2009 


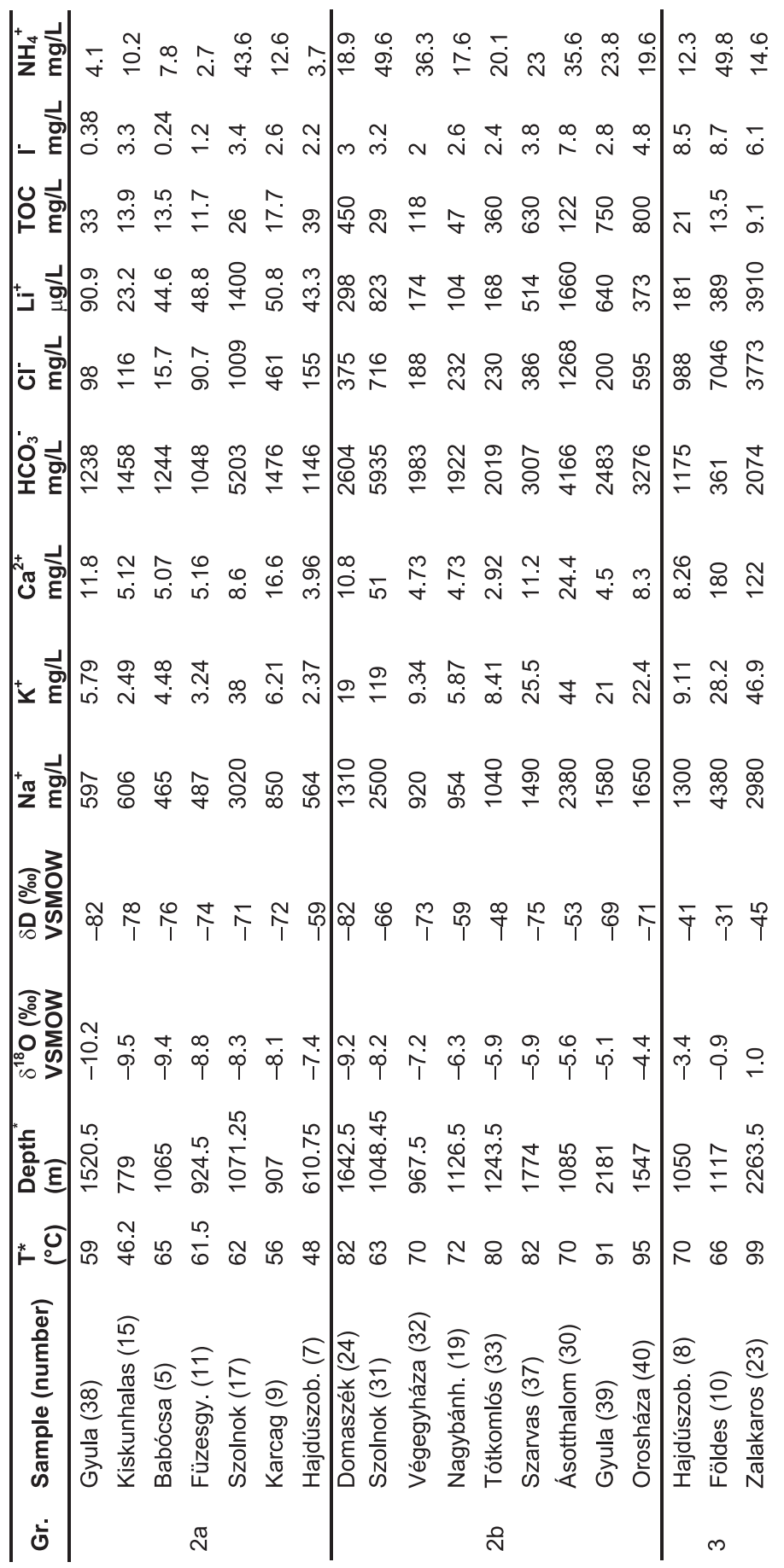




\section{Sampling and analytical techniques}

Thermal water samples were taken by the Geological Institute of Hungary from operating wells between 2001 and 2002. Several liters of water were put into clean polyethylene sampling bottles and closed hermetically. The analyses were performed within a few days while samples were stored below $4{ }^{\circ} \mathrm{C}$. For organic chemical analyses water samples were collected in 2.5-liter, solvent washed, dried $\left(200^{\circ} \mathrm{C}\right)$ glass bottles with glass stoppers. Samples were cooled during transport and stored at $4{ }^{\circ} \mathrm{C}$ till extraction within 2-3 days.

The stable isotope ratio analyses were carried out in the Institute of Nuclear Research of the Hungarian Academy of Sciences. The results are given in the conventional $\delta$ notation as the per mil (\%o) deviation of the isotope relative to known standards $\left(\delta=\left(R_{\text {sample }} / R_{\text {standard }}-1\right)^{*} 1000\right.$, where $R_{\text {sample }}$ and $R_{\text {standard }}$ are the $\mathrm{D} / \mathrm{H}$ and ${ }^{18} \mathrm{O} /{ }^{16} \mathrm{O}$ ratios in the sample and in the standard, respectively). The standard water for hydrogen and oxygen isotopes is Vienna Standard Mean Ocean Water (VSMOW).

The inorganic chemical analyses were carried out in the Geological Institute of Hungary. Dissolved inorganic compounds $\left(\mathrm{Na}^{+}, \mathrm{K}^{+}, \mathrm{Ca}^{2+}, \mathrm{HCO}^{3-}, \mathrm{Cl}^{-}\right)$were determined by ion chromatography and ICP-AES (Jobin Yvon ULTIMA 2C) spectrometry, while for trace elements ICP-MS (VG PlasmaQuad II STE) was used.

The organic chemical analyses were performed in the National Institute of Environmental Health. The organic compounds of waters were separated by chromatography and were measured from their dissolution in hexane. Identification was carried out on the basis of their mass spectra and retention times. The relative concentrations of the individual compounds were determined from the area of the peaks. The identified compounds and the cumulative concentrations of the homologue series are given in Table 2 .

Quantitative measurements were performed for the following compound groups: volatile compounds (halogenated hydrocarbons, alkylbenzenes and naphthalene), polyaromatic hydrocarbons (PAHs) and phenols. Thirty-two halogenated hydrocarbon, 14 alkylbenzene, $15 \mathrm{PAH}$ and 16 phenol standards were quantified. The volatile compounds were measured by solid phase microextraction (SPME) method with an HP 5890 GCMS on the basis of EPA 524.2. and EPA 8260 (He carrier gas; $250{ }^{\circ} \mathrm{C}$ splitless injector; oven heating: $40{ }^{\circ} \mathrm{C}$, $6{ }^{\circ} \mathrm{C} / \mathrm{min}$ to $230{ }^{\circ} \mathrm{C}, 10 \mathrm{~min}$ delay).

The amounts of polyaromatic hydrocarbons (containing 2, 3, 4 or 5 rings) were measured with high-pressure liquid chromatography (HPLC) on the basis of EPA-550.1. (Guard column: Phenomenex Security Guard $4 \times 3.0 \mathrm{~mm} 5 \mu$ C18; analytical column: Supelcosil LC-PAH $250 \times 4.6 \mathrm{~mm} 5 \mu \mathrm{C} 18 ; \mathrm{T}=35{ }^{\circ} \mathrm{C}$; ACN/water: $0 \min =50 / 50,5 \min =50 / 50,25 \min =90 / 10,45 \min =100 / 0$, $50 \mathrm{~min}=100 / 0,55 \mathrm{~min}=50 / 50,60 \mathrm{~min}=50 / 50$.)

Naphthalene was measured in two different groups with different techniques (among volatiles and PAHs, by SPME GCMS and HPLC, respectively). Phenols 
were determined by extraction and by acetate derivation (and extraction) methods with gas chromatography.

Table 2

Characteristic parameters of thermal water groups/subgroups (*average values are given)

\begin{tabular}{|c|c|c|c|c|c|c|r|r|r|}
\hline Group & Origin & $\begin{array}{c}\text { Organic matter } \\
\text { content }\end{array}$ & $\begin{array}{c}\mathbf{T} \\
\left({ }^{\circ} \mathbf{C}\right)\end{array}$ & $\begin{array}{c}\text { Toc } \\
(\mathbf{m g} / \mathbf{l})\end{array}$ & $\begin{array}{c}{ }^{*} \text { Number } \\
\text { of peaks }\end{array}$ & $\begin{array}{c}\text { *Fingerprint } \\
\text { area }\end{array}$ & $\begin{array}{c}\text { *Phenols } \\
(\mu \mathbf{g} / \mathbf{l})\end{array}$ & $\begin{array}{c}{ }^{*} \text { Alkyl- } \\
\text { benzenes } \\
(\mu \mathbf{g} / \mathbf{l})\end{array}$ & $\begin{array}{c}{ }^{*} \text { PAHs } \\
(\mathbf{m g} / \mathbf{l})\end{array}$ \\
\hline 1a & meteoric & none/small & $38-77$ & $0.7-5.2$ & 7.9 & $5.56 \times 10^{7}$ & 5 & 7 & $2.13 \times 10^{3}$ \\
\hline 1b & meteoric & some/medium & $70-97$ & $3-112$ & 80.1 & $156 \times 10^{7}$ & 2255 & 259 & $36.2 \times 10^{3}$ \\
\hline 2a & mixed & none/small & $20-62$ & $12-39$ & 19.9 & $20.8 \times 10^{7}$ & 0 & 16 & $6.92 \times 10^{3}$ \\
\hline 2b & mixed & medium/lot & $63-95$ & $29-800$ & 120.3 & $845 \times 10^{7}$ & 2987 & 683 & $147 \times 10^{3}$ \\
\hline 3 & connate & some/medium & $66-99$ & $9-21$ & 51.3 & $98.6 \times 10^{7}$ & 126 & 246 & $22.2 \times 10^{3}$ \\
\hline
\end{tabular}

\section{Relative groundwater ages: mixing of connate and meteoric waters}

The thermal waters in the Pannonian Basin are basically of two types of origin. The meteoric (or paleometeoric) waters are usually characterized by lower chlorine and more negative $\delta^{18} \mathrm{O}$ values. Isotopically heavy thermal waters with high chlorine content point to significant contribution (or even predominance) of connate waters formed during brackish period(s) of the long-lived Pannonian Lake

Meteoric waters of the last glacial are easy to recognize since these are isotopically very light (Stute and Deák 1989). These $\left(\delta^{18} \mathrm{O}=-15\right.$ to $-12 \%$ o $)$ and the younger ones can be distinguished in the meteoric group. The $\delta^{18} \mathrm{O}$ values of the waters that infiltrated during the Holocene $(-10,5$ to $-9 \%$ ) overlap with that of mixed (connate - glacial meteoric) ones. The waters with $\delta^{18} \mathrm{O}$ values close to $-10.5 \%$ fall close to the local meteoric water line (LMWL) and the isotopically heavier ones show a shift towards the supposed brackish lake water (Fig. 2). On the basis of sampling depths and this phenomenon, the waters are of mixed connate and glacial meteoric origin, not Holocene meteoric waters. In this case the LMWL was calculated on the basis of Pleistocene and Holocene waters' stable isotope data (Deák 1995) and its equation is:

$$
\delta \mathrm{D}=7.8 * \delta^{18} \mathrm{O}+6
$$

While most of the waters are mixtures of two end-members (meteoric and connate waters) of unknown proportion, and the chemical compositions were influenced by different processes (rock-water interaction) their grouping on the basis of chemical properties is not adequate. However, in a recent study three groups were set up by means of oxygen isotope values (not or much less affected by rock-water interactions): 1 . young, meteoric waters infiltrated not later than during the last glacial (Würm) $\left(\delta^{18} \mathrm{O}<-10.5 \%\right) ; 2$. mixed waters $\left(\delta^{18} \mathrm{O}=-10\right.$ to $-4.4 \%$ ); 3. old connate waters trapped in the sediments of the depositional environment (probably the Pannonian Lake) $\left(\delta^{18} \mathrm{O}=-3.3\right.$ to $\left.+0.96 \%\right)$. Strict endmembers are not known and contribution of Miocene meteoric water also cannot 


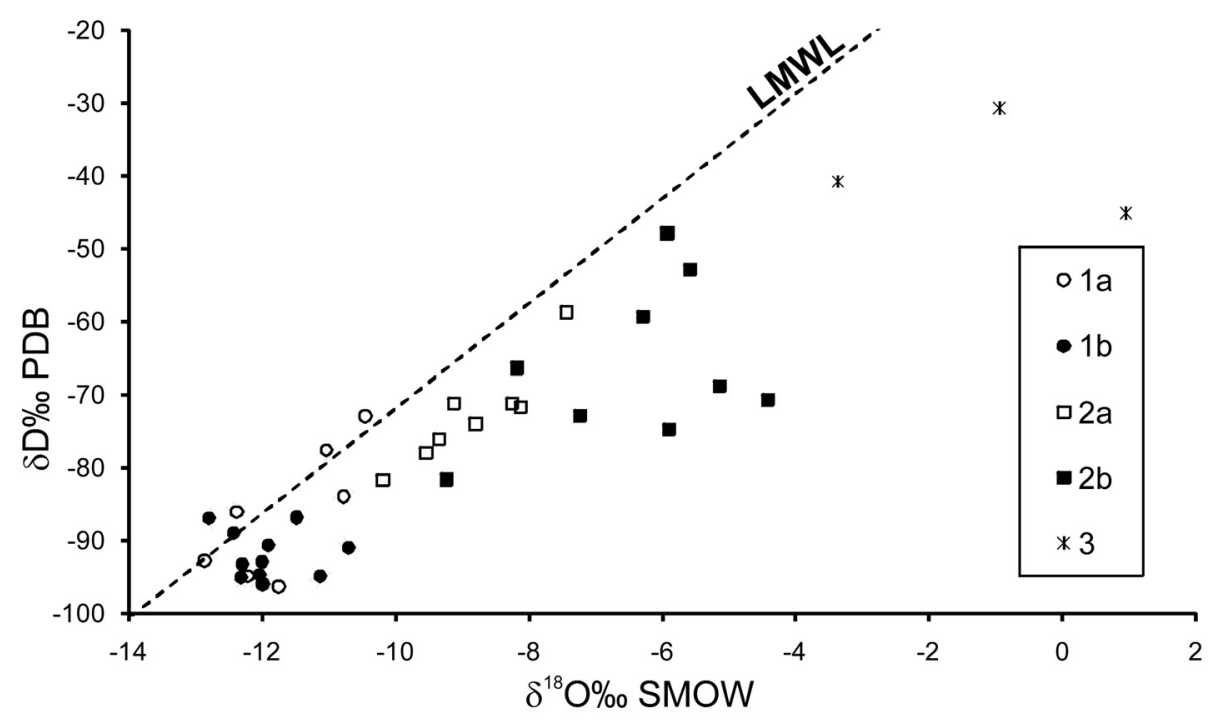

Fig 2

Stable isotope ratios of the waters

be excluded. Vetó et al. (2004b) point out that an additional difficulty in deciphering mixing processes is the fact that thermal water samples of SE Hungary commonly result from mixed production from several aquifers. This assumption affects our interpretation as well, since the waters studied by Vetô et al. (2004b) represent two-thirds of the waters included in this work.

Actually the samples of the last group can also be a mixture of two water types, but contain very small proportion of paleometeoric component. Subgroups "a" and " $b$ " (distinguished on the basis of organic compounds) are defined hereinafter.

\section{Aromatic compounds}

In groundwaters colloidal and dissolved organic compounds can be observed. Large molecular-sized, mostly humic substances exist in colloid solution. Their molecular size (association - dissociation) is influenced by the physicochemical parameters of the waters (temperature, redox potential, $\mathrm{pH}$ ).

Concentration of dissolved molecules is usually small, because of the low solubility (except for the salts of light fatty acids, e.g. acetates). Close to oil accumulations crude oil derivatives can be found in the waters, because the aromatics are soluble to some degree, and the solubility of alkanes sharply increases above $100{ }^{\circ} \mathrm{C}$. In a recent study of the thermal waters not connected to hydrocarbon fields, and above approximately $80{ }^{\circ} \mathrm{C}$, mono-, di-, poly- and heteroaromatic hydrocarbons, phenols and fatty acids (with 6 to $16 \mathrm{C}$-atoms alkyl 
chain) were identified in the samples, in some cases in fairly high concentrations $(>10 \mathrm{mg} / \mathrm{L})$.

The present paper focuses on the organic features of thermal water groups; a detailed discussion of organic components will be provided in a coming study.

We ranked the samples by "maturities" on the basis of the following parameters: 1 . increasing total phenol content, 2 . increasing total alkyl-benzene content and 3. increasing total area of fingerprint measurements (TIC - Total Ion Chromatogram of hexane extracts) (Table 2).

Average numbers of identified peaks and the area of the fingerprints in the groups are represented in columns 6 and 7 of Table 2. In columns 8-10 the total amounts of the homologue series are averaged for each group.

The total organic carbon (TOC) concentration of the samples varied between 0.7 and $800 \mathrm{mg} / 1$ (Table 2). The different concentration of (semi)volatile compounds (hereafter referred to as volatiles) were used to group the samples in "group a", for samples containing none or just a small amount of organic compounds and "group b" for samples rich in volatile organic compounds.

With the above-mentioned criteria we were able to define five types of thermal waters: (1a) young, meteoric waters, without or with low concentration of volatile organic compounds ( $\sim$ immature); $(1 b)$ young, meteoric waters, rich in organic matter ( $\sim$ mature); (2a) immature mixed waters; $(2 b)$ mature mixed waters and (3) old connate waters containing small or medium amounts of noncharacteristic organic compounds. This last group was not divided into subgroups because it contains only 3 samples. Their organic compounds are poorly identified (Table 2).

There is no tight correlation between TOC and volatile organic compounds; however, it can be observed that the immature waters are characterized by smaller maximum TOC values than mature ones (1a: $5.2 \mathrm{mg} / \mathrm{L}, 2 \mathrm{a}: 39 \mathrm{mg} / \mathrm{L}$, and 1b: $112 \mathrm{mg} / \mathrm{L}, 2 \mathrm{~b}: 800 \mathrm{mg} / \mathrm{L}$ )

The peaks summarized in "Mixture" consist of O-containing molecules not belonging to the identifiable homologue series. The origin of these oxygenated organic compounds is ambiguous and they are partly suspected to be contaminants. They always appear in small amounts and their identification is doubtful. From the results of the fingerprint measurements the average values were calculated for each group/subgroup, and the relative average distributions of the most important compound classes are summarized in Table 3.

Maturity is the average of the order of maturity, where 1 is the least, 38 is the most mature. Aliphatics contain the aliphatic hydrocarbons, mostly n-alkanes. Aromatics mean the total aromatic hydrocarbons including alkyl-benzenes, alkylindanes, tetrahydronaphthalenes, dihydronaphthalenes, alkyl-naphthalenes, alkyl-biphenyls+acenaphtene+alky-fluorenes, dihydrophenanthrenes, tetrahydrophenanthrenes, alkyl-phenanthrenes, pyrenes, fluoranthenes. Heteroaromatics contain all the heteroaromatic hydrocarbons, tetrahydrotiophenes, tetrahydrotiopyranes, benzotiophenes, dibenzotiophenes, benzofuranes, di- 
Table 3

Distribution of mean values for important compound classes in different groups/subgroups

\begin{tabular}{|c|c|c|c|c|c|c|c|c|c|c|c|c|c|}
\hline $\begin{array}{l}\text { 을 } \\
\text { ㅎํㄴ }\end{array}$ & 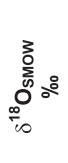 & 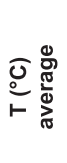 & 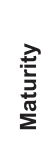 & 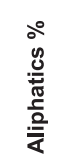 & 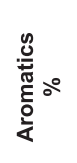 & 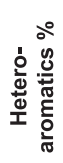 & $\begin{array}{l}\stackrel{0}{0} \\
\frac{n}{0} \\
\frac{c}{0} \\
\frac{0}{\alpha}\end{array}$ & $\begin{array}{l}\stackrel{0}{0} \\
\frac{0}{0} \\
\frac{0}{0}\end{array}$ & 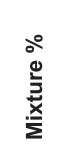 & 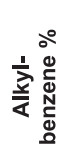 & 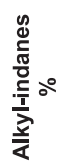 & 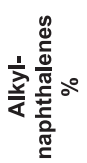 & 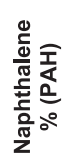 \\
\hline $1 \mathrm{a}$ & -11.6 & 57.1 & & .16 & 5.62 & 0.00 & 0. & 0.0 & 63.0 & 0.14 & 1.39 & 1.65 & 48.68 \\
\hline $1 \mathrm{~b}$ & -12 & 79.1 & 257 & 0.95 & 77.92 & 2.56 & 4.9 & 0. & 13.6 & 12.45 & 15.69 & 30.40 & 82.62 \\
\hline $2 a$ & -8.9 & 56.5 & 10.6 & 6.59 & 42.85 & 0.61 & 0.00 & 1.50 & 48.45 & 8.89 & 2.45 & 14.52 & 21.17 \\
\hline $2 b$ & -6.4 & 78.3 & 31.1 & 8.31 & 51.31 & 3.74 & 5.97 & 9.07 & 21.59 & 15.08 & 5.57 & 21.93 & 95.07 \\
\hline 3 & -1.1 & 78.3 & 22.3 & 0.03 & 71.84 & 5.36 & 0.00 & 0.00 & 22.77 & 7.15 & 15.84 & 29.97 & 37.10 \\
\hline
\end{tabular}

benzofuranes, alkyl-carbazoles etc. Phenols are the total phenol contents, Acids are organic acids, mainly fatty acids. The Mixture contains all other compounds, regularly phtalic acid esters. Their identification is usually doubtful because of coelutions.

These homologues were measured in the 38 water samples. In Table 3 the proportions of alkyl-benzenes, alkyl-indanes and alkyl-naphthalenes are shown, and naphthalene proportion in PAHs. Every parameter is the average of one group.

On the basis of the data the five subgroups differ sharply from each other. The average maturity of the younger waters is smaller as reflected by the less number of peaks and smaller fingerprint area values; however, the outflow temperatures are in the same range.

The less mature samples are characterized by relatively higher aliphatic and mixture contents. The aliphatic hydrocarbons identified in the samples $\left(\mathrm{C}_{18}-\mathrm{C}_{36}\right)$ are not (or very slightly) soluble in water, so these compounds are bound to hydrophobic particles of colloidal matter (e.g. hydrophobic parts of humic and fulvic acids) and they are not the products of the organic matter maturation occurring in the groundwater. The relative concentration of O-containing (unidentifiable) compounds decreases with maturity. This may suggest that such compounds may be transformed (probably into aliphatic or aromatic hydrocarbons, including phenols) with increasing temperature.

The major components of the mature waters are aromatic hydrocarbons and heteroaromatic compounds. Phenols and organic acids can be identified only in the hottest waters. In the earlier stage of the maturation process the alkylbenzenes, alkyl-indanes and alkyl-naphthalenes are dominant. The proportion of the naphthalene among PAHs increases with maturation. It must be mentioned that in the case of meteoric waters (group 1) there is no difference in the $\mathrm{O}$ content between the two subgroups, but in the case of mixed waters, the more mature ones are relatively older (contain connate water in a relatively larger proportion). The organic matter of the oldest waters (group 3) is not the most mature although the temperatures do not differ. This phenomenon can be explained by the completely different origin of the water and organic matter of group 3 waters. 
We have calculated the average heavy hydrocarbon gas $\left(\mathrm{C}_{2+}\right)$ contents for the thermal water subgroups $1 \mathrm{a}, \mathrm{b}$ and $2 \mathrm{a}, \mathrm{b}$ from the data reported by Vetô et al. (2004a). The differences in $\mathrm{C}_{2+}$ contents between the above-listed subgroups (Table 4 ) are very similar to those in average aromatic contents. Since $\mathrm{C}_{2+}$ gases are obviously of thermogenic origin, these similarities reinforce our assumption about "in situ" thermogenic origin of the aromatic compounds present in the thermal waters studied.

\section{Characterization of thermal waters}

The geochemistry of the Hungarian thermal waters was studied by several authors (e.g. Kárpáti et al. 1995, 1996a, b, 1999; Varsányi et al. 2002; Varsányi and Kovács 2009; Vetố et al. 2004b). The results of this study have shown a similar distribution of $\mathrm{HCO}^{-}$concentration and sodium-bicarbonate ratios. Although the positions of the waters in their flow paths is not known, we can observe that the amount of $\mathrm{HCO}^{-}$does not have a strict correlation with depth, but waters from greater depths usually contain more dissolved carbonate.

The former conclusion was extended by the recognition of the relationship between temperature, hydrogen carbonate concentration and the subgroups formed on the basis of organic matter content as plotted in Fig. 3. The samples

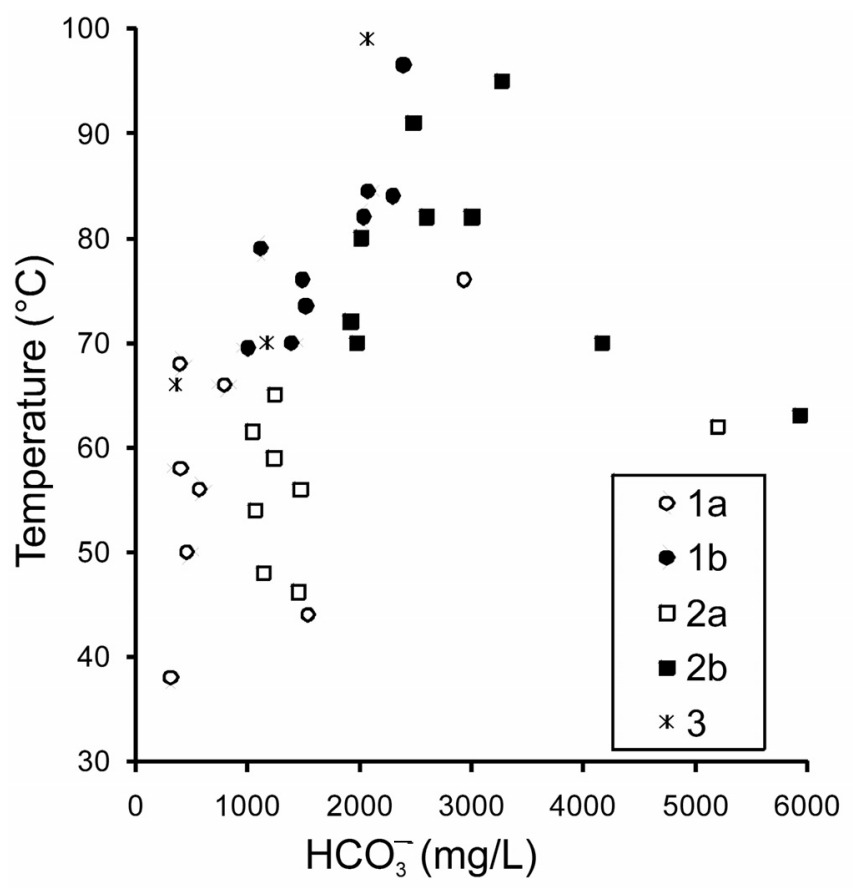

Fig 3

$\mathrm{HCO}^{-}$content versus temperature 


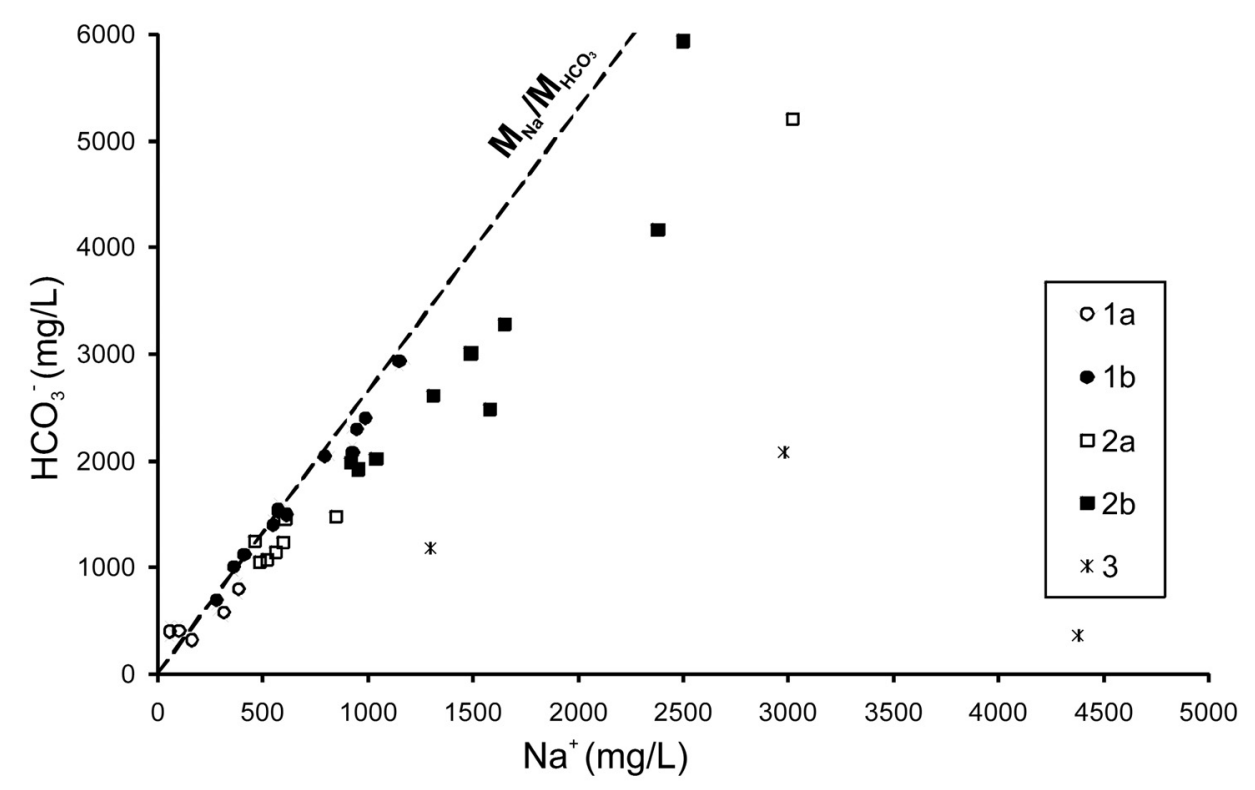

Fig. 4

$\mathrm{Na}^{+}$and $\mathrm{HCO}^{-}$content

containing mature organic matter ("b" subgroups) are regularly characterized by higher temperature and $\mathrm{HCO}^{+}$content. The $\mathrm{CO}_{2}$ produced by the decomposition of organic matter increases the dissolution of carbonate present in the sediments. The temperature-dependent decay of organic matter produces small molecular size, well-soluble, volatile organic compounds as well.

As dominant anion and cation, the amount of hydrogen carbonate and sodium ions show good correlation in the case of meteoric and less mixed water samples. As the proportion of the older (or connate) water component increases, the values diverge from the line representing the atomic weight ratios of $\mathrm{Na}+$ and $\mathrm{HCO}^{-}$. The connate waters of group 3 differ sharply from others, while the connate waters are of sodium-chloride types, although their hydrogen-carbonate content is moderate.

In the thermal waters the sodium/chloride ratio can be three orders of magnitude higher than in seawater (Fig. 5). Two sample groups lay close to the line representing values of rainwater to seawater. In the case of group 3 this can be further evidence for their mostly brackish (or seawater) origin. In these waters chloride concentrations are higher than $1000 \mathrm{mg} / \mathrm{l}$. Vetô et al (2004b) consider these as waters remains from the brackish Pannonian Lake.

The three other samples (close to the lower left corner) containing less than 200 $\mathrm{mg} / \mathrm{l}$ chloride are greatly enriched in calcium. These waters fall below the line representing diluted seawater, and are depleted in sodium. These are warm karst 


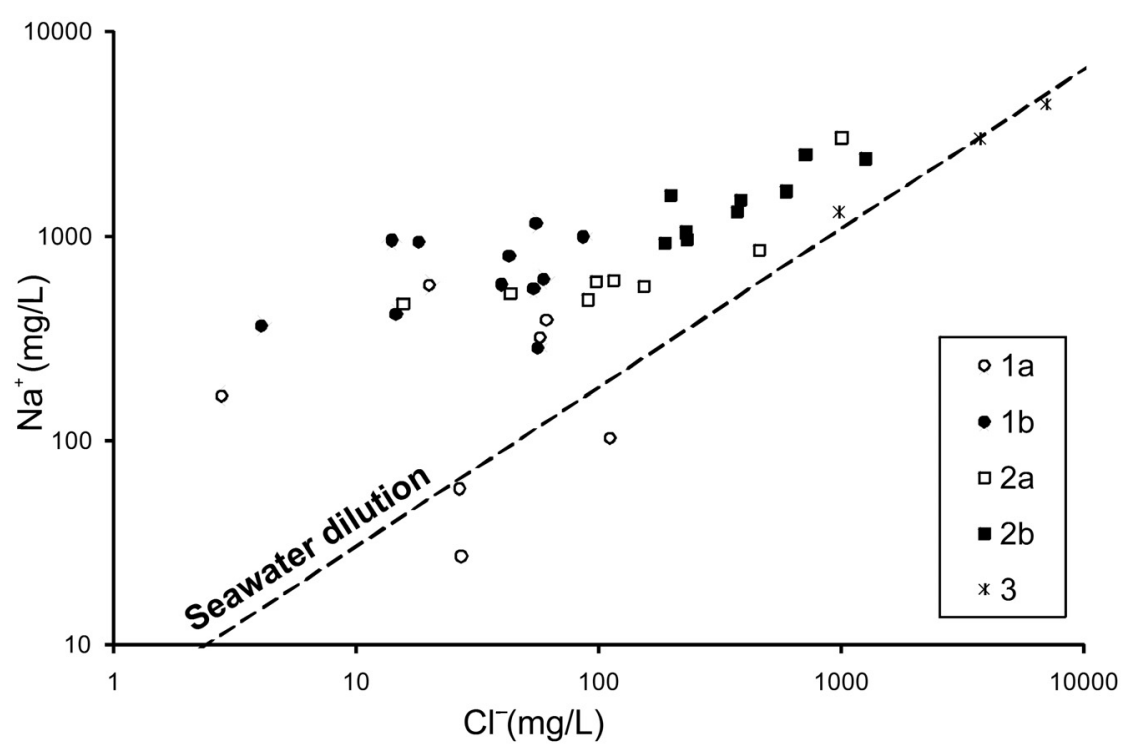

Fig. 5

Chloride and sodium concentrations

waters, which are not affected by ion-exchange and feldspar dissolution processes as described later. Karst waters usually do not contain any mature organic matter; their TOC values are also among the smallest.

The above-mentioned $\mathrm{CO}_{2}$ production during the decomposition of organic matter enhances the hydrolysis of feldspars, which is one the most important $\mathrm{Na}^{+}$sources. The sodium concentration in the waters of subgroup "b" containing more volatile organic compounds (mature organic matter), is higher than in waters without small-sized organic compounds. Although beside this sodiumproducing hydrolysis process, clay mineral alteration and cation exchange can also increase the proportion of $\mathrm{Na}^{+}$, the relationship between $\mathrm{K}^{+}$and $\mathrm{Li}^{+}$(Fig 6), and the loose correlation between $\mathrm{Na}^{+}$and $\mathrm{K}^{+}$or $\mathrm{Na}^{+}$and $\mathrm{Li}^{+}$, supports the thesis that more than one effect is responsible for sodium enrichment.

Appearance of volatile organic compounds is bound to a temperature threshold, which confirms the former hypothesis about the behavior of these polyaromatic hydrocarbons. In Fig. 7 the $\sim 70{ }^{\circ} \mathrm{C}$ temperature threshold sharply separates the waters containing and those not containing volatile organic compounds. It must be mentioned that the temperature values are outflow temperatures. Bottom-hole temperatures are at least $15-30{ }^{\circ} \mathrm{C}$ higher.

The total organic carbon contents (TOC) in "b" subgroups are approximately one order of magnitude higher than those in "a" samples (Fig. 8). This indicates that organic content is influenced by the age (and so by the length of the flowpath) as well, but the appearance of small molecular-sized, volatile compounds is only controlled by the temperature. The TOC concentrations in 
282 J. Fekete et al.

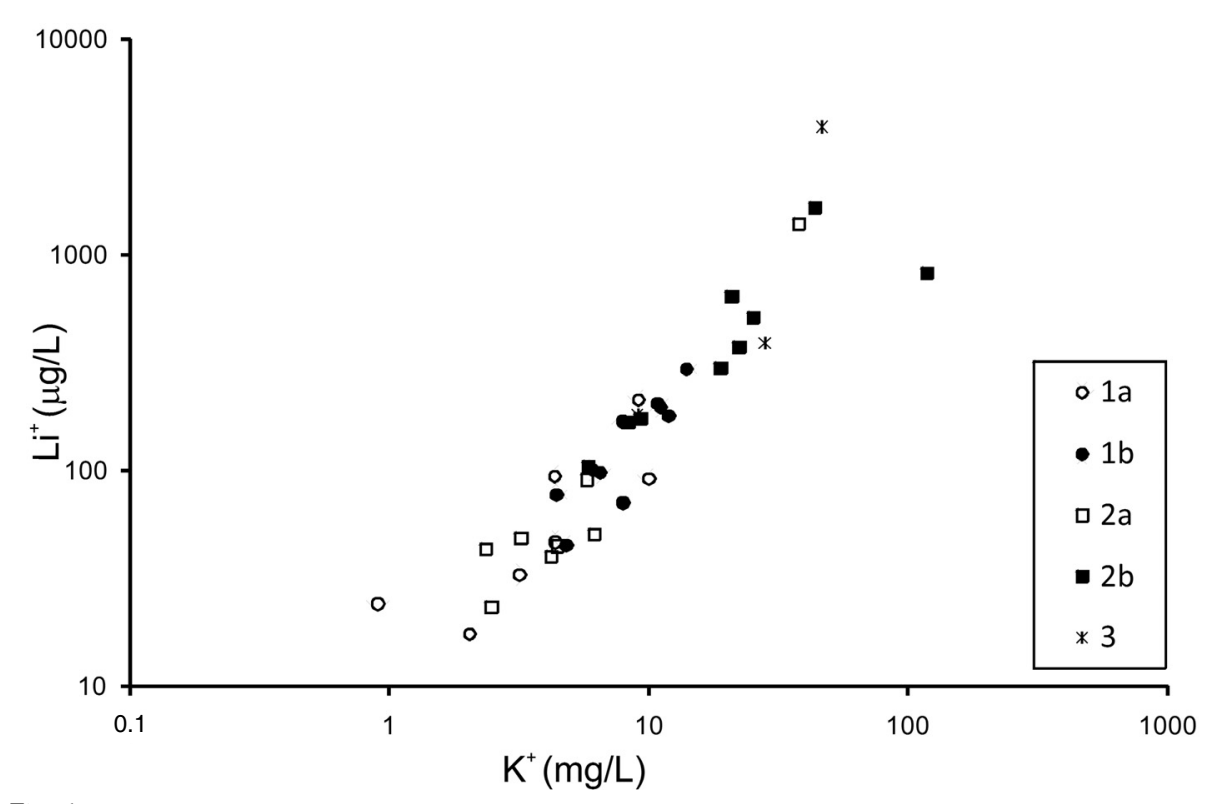

Fig. 6

Potassium and lithium concentrations

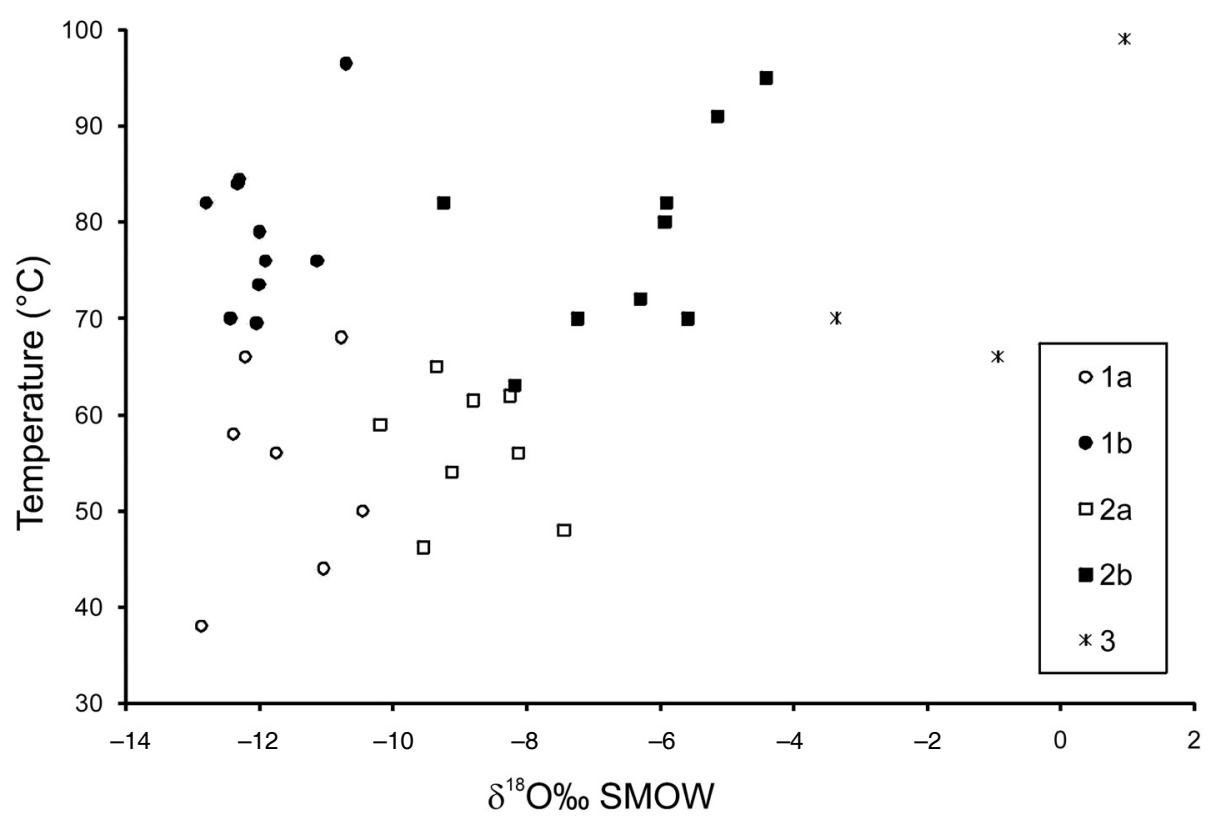

Fig. 7

Temperatures of the thermal water groups

Central European Geology 52, 2009 


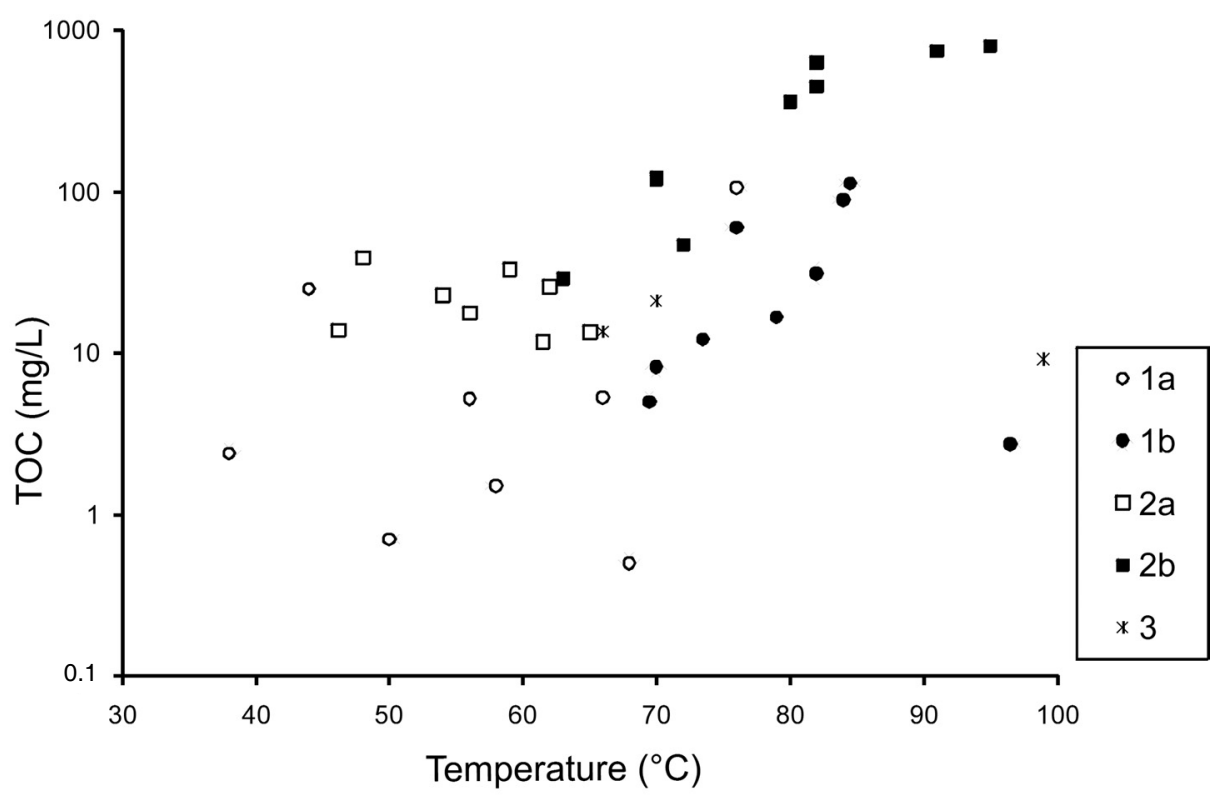

Fig. 8

TOC concentration versus temperature

groups $1 \mathrm{~b}$ and $2 \mathrm{a}$ is in a similar range, but for the difference in temperature, in the 2 a samples maturity did not produce decomposition products, i.e. small molecular-sized volatile compounds.

The origin of the organic material can vary. TO begin with the soluble organic components of the soil (e.g. humic substances) dissolve in the infiltrated rainwater. Through the flowpath the waters may interact with the dispersed organic matter of the sediments or with organic matter accumulations (lignite for example) developing a complex organic facies.

Iodine usually correlates with the organic content, because I is accumulated by living organisms in high concentrations. In a recent study iodine concentration was found not to correlate with TOC and volatile organic compound classes, although their organic origin is possible because the waters are greatly enriched in I compared to seawater $(0.06 \mathrm{mg} / \mathrm{l}$ average) (Fig. 9). The samples of group 2 (and 3) are characterized by high iodine concentrations independently of their organic compounds, suggesting an earlier decomposition of the iodinecontaining biota at relatively low temperature.

This phenomenon supports the conception that the flowpath (higher temperature, longer residence time) influences the organic facies, either by way of maturation or through interference with more types of organic material. During its evolution the Pannonian Lake became a brackish, than a freshwater system. Iodine concentration decreased with decreasing salinity, and marine plants (or algae) rich in iodine were replaced by freshwater and terrestrial plants containing generally less of it (Fuge and Johnson 1986). 


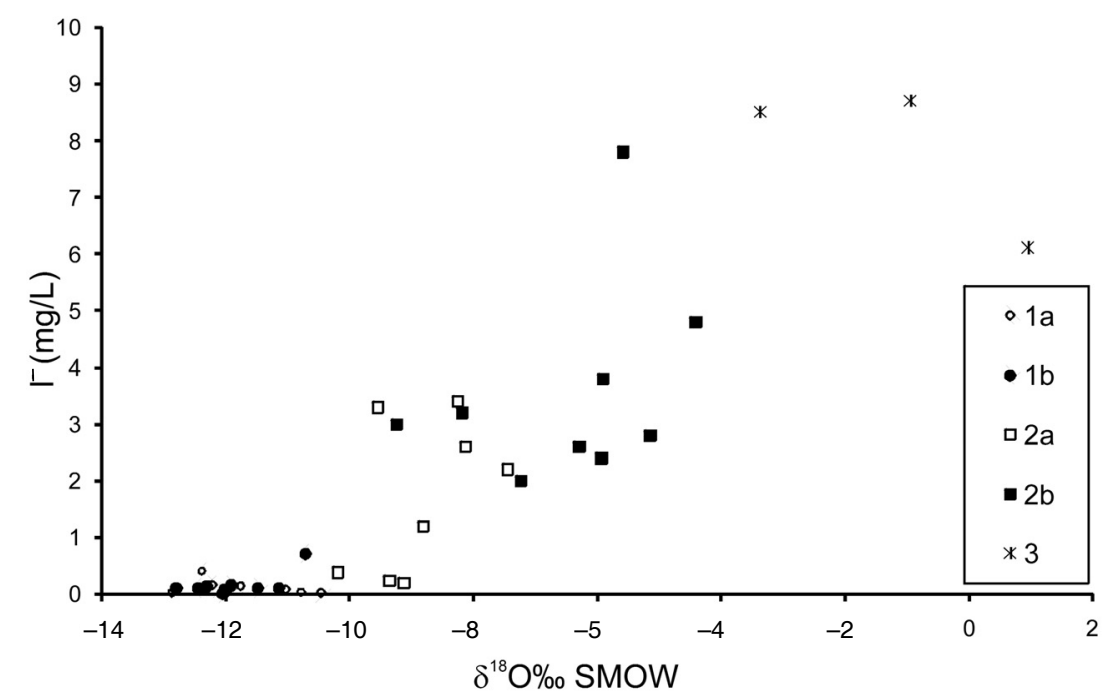

Fig. 9

Iodine contents of the water groups

\section{Summary}

In this contribution the impact of the maturity (decomposition) of organic matter on water-rock interaction processes was studied and parameters depending on organic content (quality and quantity) were examined. The molecular composition of the dissolved organic matter was briefly presented. Average values were calculated to characterize inorganic contents and the facies influencing effect of temperature in groups and subgroups.

The decomposition of organic matter increases the dissolution of carbonates and the hydrolysis of feldspars through the increase of dissolved carbon dioxide concentration, and produces hydrocarbon gases $\left(\mathrm{C}_{2+}\right.$ included $)$ and small molecular-sized, water-soluble aromatic organic compounds as temperature exceeds a given threshold value.

The origin of the dissolved organic matter may be different in the waters, varying with different relative ages and with different proportions of mixing waters.

Table 4

Average hydrocarbon gas contents of thermal waters in different groups/subgroups

\begin{tabular}{|c|c|c|c|c|}
\hline \multirow{2}{*}{$\begin{array}{c}\text { Group } \\
\text { (nr. of samples) }\end{array}$} & \multicolumn{2}{|c|}{$\mathbf{C}_{2+} \mathrm{l} / \mathrm{m}^{3}$ water } & \multicolumn{2}{c|}{$\mathbf{C}_{2+} /$ methane *100 } \\
\cline { 2 - 5 } & average & $\min -\max$ & average & $\min -\max$ \\
\hline 1a (4) & 0.04 & $0.014-0.16$ & 0.1 & $0.017-0.3$ \\
\hline $1 \mathrm{~b}(5)$ & 0.71 & $0.028-1.65$ & 0.51 & $0.11-0.9$ \\
\hline 2a (6) & 0.38 & $0.018-1.02$ & 0.14 & $0.016-0.46$ \\
\hline 2b (7) & 1.86 & $0.04-10.24$ & 0.94 & $0.21-1.22$ \\
\hline 3(2) & & $0.003-2.07$ & & $0.017-0.48$ \\
\hline
\end{tabular}


However, a temperature threshold around $70{ }^{\circ} \mathrm{C}$ (outflow temperature) can be observed in two groups, below which the mentioned organic compounds do not occur.

The organic matter in old connate waters differs from that of the other two groups, although in some cases they show similar characteristics to meteoric waters and in others to mixed waters. More samples need to be studied from this group to describe their general features.

\section{Acknowledgement}

This work was funded by the Hungarian Scientific Research Fund (OTKA) through grant T 048829 .

\section{References}

Deák, J. 1995: A felszín alatti vizek utánpótlódásának meghatározása izotópos módszerekkel az Alföldön (Determination of recharge of groundwater on the Great Hungarian Plain by isotope techniques). - VITUKI Zárójelentés, pp. 28. (In Hungarian.)

Fuge, R., C. Johnson 1986: The geochemistry of iodine - a review. - Environmental Geochemistry and Health, 8/2, pp. 31-35.

Kárpáti, Z., Cs. Sajgó, I. Vető, G. Klopp, I. Horváth 1995: Identification of various organics in thermal waters in the Pannonian Basin. Preliminary reports. - In: Grimalt, J.O., C. Dorronsoro (Eds): Organic Geochemistry Developments and applications to energy, climate, environment and human history. A. I. G.O. A. Donostia-San Sebastian, pp. 594-596.

Kárpáti, Z., I. Vetô, Cs. Sajgó 1996a: Organic microcomponent composition of thermal waters in Hungary. - Egészségtudomány, 60/4, pp. 356-364. (In Hungarian.)

Kárpáti, Z., I. Vető, Cs. Sajgó 1996b: A hazai termálvizek szerves mikrokomponens vizsgálatainak újabb eredményei (New results on organic micro-components of Hungarian thermal waters). In: Dudinszky L.-né (Ed.) A víz és a vízi környezetvédelem a Kárpát-medencében. - Magyar Hidrológiai Társaság, pp. 811-843. (In Hungarian.)

Kárpáti, Z., Cs. Sajgó, I. Vetô, G. Klopp, I. Horváth 1999: Organic matter in thermal waters of the Pannonian Basin - A preliminary report on aromatic compounds. - Organic Geochemistry, 30, pp. 701-712.

Stute, M., J. Deák 1989: Environmental isotope study $\left({ }^{14} \mathrm{C},{ }^{13} \mathrm{C},{ }^{18} \mathrm{O}\right.$, D, noble gases) on deep groundwater circulation systems in Hungary with reference to paleoclimate. - Radiocarbon, 31/3, pp. 902-918.

Tóth, J., I. Almási 2001: Interpretation of observed fluid potential patterns in a deep sedimentary basin under tectonic compression: Hungarian Great Plain, Pannonian Basin. - Geofluids, 1, pp. $11-36$.

Varsányi, I., L. Ó Kovács, Z. Kárpáti, J.M. Matray 2002: Carbon forms in formation waters from the Pannonian Basin, Hungary. - Chemical Geology, 189/3-4, pp. 165-182.

Varsányi, I., L. Ó Kovács 2009: Origin, chemical and isotopic evolution of formation water in geopressured zones in the Pannonian Basin, Hungary. - Chemical Geology, 264, pp. 187-196.

Vetô, I., I. Futó, I. Horváth, Zs. Szántó 2004a: Late and deep fermentative methanogenesis as reflected in the H-C-O-S isotopy of the methane-water system in deep aquifers of the Pannonian Basin (SE Hungary). - Organic Geochemistry, 35/6, pp. 713-723.

Vető, I., I. Horváth, Gy. Tóth 2004b: Outlines of the geochemistry of Hungarian Thermal Waters. Hungarian Journal of Chemistry, 109-110, pp. 199-203. (In Hungarian.) 